\title{
L2 Arabic Teachers' Attitude toward the Communicative Language Teaching at King Abdulaziz University
}

\author{
Anwar S Aljadani \\ Correspondence: Anwar S Aljadani, King Abdulaziz University, Kingdom of Saudi Arabia.
}

Received: May 26, 2020

doi:10.11114/ijce.v3i2.4877
Accepted: June 16, $2020 \quad$ Online Published: June 17, 2020

URL: https://doi.org/10.11114/ijce.v3i2.4877

\begin{abstract}
Second language acquisition (SLA) researchers, language teachers and teacher trainers aim to develop an approach through which languages are effectively taught in the classroom. This paper provides an overview of Communicative Language Teaching (CLT) including its definition, advantages and disadvantages as well as some criticisms made against it. It aims to investigate L2 Arabic teachers' attitude towards CLT at King Abdulaziz University. The current data were assembled via teachers' questionnaire. It was found out that in spite of revealing the agreements in the majority of the statements which infers a positive attitude towards CLT, the participants stated that CLT is not suitable and preferable. Several explanations were provided to justify this statement. The provided explanations led to assume that the unsuitability and the dispreference of CLT are built on practical constraints which could be overcome.
\end{abstract}

Keywords: second language acquisition, communicative language teaching, teaching Arabic as a second language, teaching language approaches and teachers' attitude towards communicative language teaching

\section{Introduction}

The recent twenty years have increasingly witnessed a rapid advance in the field of CLT which is one of the prominent topics of current discussion in second language (L2) teaching. This approach can be largely defined by two key elements: First, successful language learning does not rely solely on good materials and good teaching but also on the general and individual strategies employed by students; Second, that descriptions of language as an independent and unitary system have been replaced by descriptions that perceive language as a form of social activity (Ellis, 1982). Since Nunan (2004) argued that language is not only a crucial resource of creating meaning but also a tool of communication, it is becoming increasingly difficult to ignore CLT.

This paper has been organised in the following way: it, first, concentrates on definition of CLT, shedding light on the advantages and the disadvantages of CLT, followed by outlining and engaging with some of the criticisms of CLT. It, then, presents the research questions and gives detailed descriptions of the methodology uitilised to investigate L2 Arabic teachers' attitude towards CLT. The following section lays out and discusses the findings. Finally, the conclusion is revealed.

\section{Definition and Development of CLT}

The origins of CLT can be traced to the late 1960s, when British Applied Linguists proposed that, within language teaching, there was a need to concentrate upon communication rather than just concentrating upon mastery of structures. Wilkins (1972), analysed the communicative meanings that learners needed to understand and express rather than describing the core of language through the traditional concepts of grammar and lexical items. In other words, he tried to demonstrate the systems of meanings that lie behind the communicative uses of language. He described two sorts of meanings: notional categories and categories of communicative function. Since 1970, CLT has expanded to become a general approach that aims to make communicative competence the objective of language teaching. Consequently, for some researchers, CLT means little more than an integration of grammatical and functional teaching (Richards \& Rodgers, 2001). Littlewood argued that "one of the most characteristic features of CLT is that it pays systematic attention to functional as well as structural aspects of language" (1981:1).

CLT could also be defined in terms of process, as it implies using procedures where learners work in groups, employing available language resources in problem solving tasks. A key aspect of definitions, however, is its necessarily socially interactive element. As the Hong Kong Curriculum Development Committee (1981) proposed communicative purposes may be of many different kinds. What is essential in all of them is that at least two parties are involved in an interaction 
or transaction of some kind where one party has an intention and the other party expands or reacts to the intention.

It is necessary to focus in detail on four main aspects of teaching languages via CLT perspective: the syllabus, types of learning, teaching activities, the role of the learner and the role of the teacher.

$>$ The syllabus: The notional syllabus in CLT specifies the semantic-grammatical categories and the categories of communicative functions that the learner needs to express. Subsequently, this syllabus has been developed to include planned learning objectives (Wilkins, 1976). This is not the only type of CLT syllabus, however, as others can also be used. These include, for example, 'structures plus function', 'functional' and 'learner-generated' as well as 'task-based'. While task specification and task organisation are standard within CLT syllabus design, the possibility also exists of learners creating their own personal syllabus in relation to their own learning needs and communicational resources (Richards \& Rodgers, 2001).

$>$ Types of learning and teaching activities: There is an enormous range of exercises and activities. However, classroom activities usually focus on completing tasks that are mediated by language or include the negotiation and sharing of information (Richards \& Rodgers, 2001).

$>$ The role of the learner: The role of the learner has been described by Breen \& Candline (1980) as that of the negotiator. They argued that the learner's role emerges from a process of negotiation between elements such as classroom procedures, group activities and the object of learning "the implication for the learner is that he should contribute as much as he gains, and thereby learn in an interdependent way" (1980:110).

$>$ The role of the teacher: The teacher should facilitate the communication process between learners in the classroom, and between participants in different activities. An additional role for the teacher is to act as an individual participant within the learning-teaching group. These main roles then lead to secondary functions: Firstly, teachers have to organise the resources required for lessons; secondly, they should guide the classroom activities; and finally, they ought to contribute in terms of appropriate knowledge and abilities in order to observe and experience the nature of learning (Breen \& Candline, 1980).

\section{The Advantages and Disadvantages of CLT}

CLT can be perceived as having great benefits as a teaching approach. One of the advantages associated with this approach is the way that students are trained to use all key language skills - listening, speaking, reading and writing - in a 'real-life' context. Teachers are able to set up situations where communicative activities enable learners to improve these skills and adapt them to other environments (Jin, 2007). Another advantage of CLT is that it facilitates students to gain independence. This is important, as Jin (2007) argued that learners have to use language without assistance in real-life situations. This independence is also taken further by giving learners the opportunity to focus on activities relevant to their own learning needs.

On the other hand, CLT approaches have also been shown to have some disadvantages. Perhaps the most prominent disadvantage of CLT is that it has not been proven to work successfully in non native-English speaking countries. For instance, $\mathrm{Li}$ (1997) stated that CLT was designed for second language rather than for foreign language teaching (i.e. for use in English speaking countries). Moreover, Sun \& Cheng (2002) showed how -due to the success of the approach in English Second Language (ESL) classrooms in English speaking countries- CLT approaches were adopted in Chinese classrooms. In China, the approach was deemed to be far less successful, and the approach has failed to entice regional teachers and learners in non-English speaking countries (Penner, 1995). Other elements such as class size should also be taken into consideration. In China, for example, classes commonly have at least 50 students, and English classes last generally only for 45 minutes. Each student, therefore, might speak in class, on average, for less than a minute. This would make it difficult to implement a successful CLT approach in this context (Jin, 2007).

\section{Some of the criticisms made against CLT}

There have been criticisms made against CLT. One is that it creates problems of classroom management. As it implies a great deal of student interaction, this can lead to a noisy and difficult to control classroom environment. Carless (2004: 656) argued that "concerns over noise and discipline inhibited task- based teaching". Other criticisms focus on problems with the process of learning itself. Some studies, such as Carless (2004) and Lee (2005), suggested that students sometimes avoid using second language skills when engaged in communication tasks, relying instead on their native-tongue in order to overcome communication problems. This defeats the object of practicing the target language in a communicative context. A similar critique comes from Seedhouse (1999), who argued that learners will use the minimal language skills necessary in order to complete the communicative task. While this creates language competence, it does not necessarily place great demands on developing and improving this basic competence. Lee (2005) found that learners in a South Korean classroom, engaged in communicational tasks, produced language at the minimal necessary level for completing the task, avoiding difficulties wherever possible. His study also raised another 
issue by arguing that interaction was often dominated by one or two students, therefore not allowing full participation and language use on behalf of the whole class.

A criticism in much of the literature on CLT relates to its definitions of meaning and use. A fundamental assumption of CLT is that the early language teaching approaches did not cope with meaning. Meaning cannot be defined sufficiently, according to a CLT approach, through a focus solely on grammar and dictionary definition, it must include an understanding of language in use (Swan, 1985). Such an argument can be illustrated through a focus on utterances that have one kind of propositional meaning and a different kind of function. If a mother says to her son, for example, 'your coat is on the floor' she is not merely making a declarative statement but is issuing a command 'pick it up'. A definition of meaning that did not account for language in use would not be able to make sense of the implications of such a statement. Widdowson, (1978, cited in Swan, 1985), argued that a learner cannot appropriately understand an utterance if they know only its structural and lexical meaning. In order to realise its real value in a particular situation, s/he must have learnt the rules regarding how the utterance might be used. Swan (1985), however, criticised this argument, proposing instead that such communicative understanding is based on experience and common-sense rather than language-specific knowledge. A student, according to Swan's argument, could understand the command implications of the declarative utterance without necessarily having to study the language-in-use (discourse) aspect of meaning.

\section{Research Questions}

The current study intends to explore the extent to which L2 Arabic teachers consider CLT as a suitable and preferable approach to teach Arabic as an L2 at King Abdulaziz University. It also seeks to reveal the influence of the practical and educational environment constraints on teachers' attitude towards CLT.

\section{The Methodology}

\section{Participants}

Twenty Arabic teachers (16 males and 4 females) were recruited to respond to the current study questionnaire. Their ages ranged from 35 to 55. They have been teaching Arabic for a while no less than ten years and work for the King Abdulaziz University as L2 Arabic teachers.

\section{Materials}

To perceive the teachers' attitudes and perceptions towards CLT, three main principles were investigated: the concept of implementing CLT, teacher roles and needs as well as the adequacy of educational environment. The questionnaire comprises 13 items to investigate the aim of the current study. Each item is followed by a five-point Likert scale from 5 (completely agree) through 3 (neutral) to 1 (completely disagree). The three following sentences are examples fom the questionnaire:

$\checkmark \quad$ Teaching should focus on fluency rather than accuracy.

$\checkmark$ Students should be at the centre of knowledge transmission. Teacher should be their facilitator.

$\checkmark$ Teachers should strongly encourage the students to learn by themselves through struggling to communicate.

\section{Results}

This section presents an overview of the study findings. Its main aim is to find out to what extent L2 Arabic teachers have a positive \negative attitude toward CLT. The participants' responses under 'completely agree' and 'agree' are dealt with as an agreement and those under 'disagree' and 'completely disagree' are dealt with as a disagreement. The findings are presented in three tables. Table 1 shows the responses on the concept of implementation of CLT, Table 2 reveals the responses on the teachers' roles and needs in the implementation of CLT and Table 3 presents the responses on the adequacy of the educational environment inside and outside the classroom.

Table 1. The responses on the concept of implementation of CLT

\begin{tabular}{c|c|c|c|c|c}
\hline Q & Completely agree & agree & Neutral & Disagree & $\begin{array}{c}\text { Completely } \\
\text { disagree }\end{array}$ \\
\hline The focus on fluency & 3 & 9 & 3 & 5 & 0 \\
\hline $\begin{array}{c}\text { The centre of knowledge } \\
\text { transmission }\end{array}$ & 3 & 7 & 6 & 4 & 0 \\
\hline The best teaching approach & 2 & 3 & 3 & 8 & 4 \\
\hline Desire to adapting CLT & 8 & 2 & 6 & 3 & 1 \\
\hline
\end{tabular}

Table 1 presents the experimental data on the concept of implementation of CLT. The first statement is that the extent to which the participants agree on the focus upon the fluency rather than accuracy. The agreement was obtained by twelve 
out of twenty. What is striking about the figures in this table can be shown in the responses on the statement that students are supposed to be the centre of knowledge transmission whereas their teachers are considered as facilitators. Half of the participants agreed and above a quarter could not decide. The third point says that CLT is the best teaching approach. More than half of the participants did not agree while quarter of them agreed. What stands out in the table is the concern about the participants' reluctance to implementing CLT as it does not prepare students for the exams. Half of the participants agreed and six participants were neutral.

Table 2. The responses on teachers' roles and needs

\begin{tabular}{c|c|c|c|c|c}
\hline Q & Completely agree & agree & Neutral & Disagree & $\begin{array}{c}\text { Completely } \\
\text { disagree }\end{array}$ \\
\hline Correcting students' mistakes & 4 & 9 & 1 & 2 & 4 \\
\hline $\begin{array}{c}\text { Students encouragement to } \\
\text { self-learning }\end{array}$ & 6 & 7 & 4 & 3 & 0 \\
\hline $\begin{array}{c}\text { teachers' non-teaching } \\
\text { responsibilities }\end{array}$ & 10 & 6 & 3 & 1 & 0 \\
\hline Teachers training & 12 & 7 & 1 & 0 & 0 \\
\hline
\end{tabular}

Table 2 shows the responses on the teachers' roles and needs in the implementation of CLT. The participants showed a significant agreement on the statement that teachers ought not to correct students' mistakes unless they breakdown the communication by thirteen participants out of twenty while six participants disagreed. Moreover, thirteen agreements can be observed on the point that teachers have to encourage their students to learn by themselves through struggling to communicate and nearly quarter of the participants was neutral. Interestingly, the majority of participants agreed with the statement that teachers have non-teaching responsibilities which may lead to the improper preparation for the lessons. The final striking observation to emerge from the Table 2 is that nearly all the participants agreed that teachers should be trained to effectively implement CLT.

Table 3. The responses on the adequacy of educational environment

\begin{tabular}{c|c|c|c|c|c}
\hline $\mathrm{Q}$ & Completely agree & agree & Neutral & Disagree & $\begin{array}{c}\text { Completely } \\
\text { disagree }\end{array}$ \\
\hline $\begin{array}{c}\text { The concentration of textbook } \\
\text { on the language skills }\end{array}$ & 4 & 7 & 1 & 7 & 1 \\
\hline $\begin{array}{c}\text { The suitability of classrooms } \\
\text { for CLT }\end{array}$ & 2 & 5 & 2 & 3 & 8 \\
\hline The insufficiency of timetable & 10 & 3 & 4 & 3 & 0 \\
\hline CLT and exams preparation & 10 & 3 & 6 & 1 & 0 \\
\hline $\begin{array}{c}\text { The suitability of students } \\
\text { number in the classroom }\end{array}$ & 0 & 2 & 5 & 3 & 10 \\
\hline
\end{tabular}

Table 3 provides the responses on the adequacy of educational environment to implementing CLT. In the response to the concentration of textbook on the language skills, thirteen participants agreed while eight did not. The majority of respondents did not agree about the suitability of classrooms for CLT though seven respondents agreed. One of the most striking results to emerge from the above table is that the insufficiency of timetable and the improper exams preparation in CLT obtained a significant agreement by nearly $75 \%$ of the responses. It is also interesting to observe that nearly three quarter of the responses disagreed in the suitability of students' number in the classroom.

\section{Discussion}

Teachers' attitude has a fundamental role in the implementation of any language teaching approaches including CLT. The current study was carried out to investigate the attitude of L2 Arabic teachers at King Abdulaziz University towards the implementation of CLT to teach Arabic as an L2. The data were collected by a questionnaire which investigated the teachers' attitude in three domains: the concept of implementation of CLT, teachers' roles and needs as well as the adequacy of educational environment as a challenge in the implementation of CLT.

Although the teachers showed an overview of a positive attitude as there are agreements on the importance of the idea that L2 teachers should focus on the fluency rather than the accuracy, and the idea that L2 learners are supposed to be the centre of knowledge transmission whereas their teachers are considered as facilitators, there is a tendency of unsuitability and dispreference of CLT. There are several potential explanations for the unsuitability and the 
dispreference of CLT. A first potential explanation might be that it does not perfectly prepare students for exams (Jean, 2009). Moreover, the current respondents probably believe that a variety of lessons cannot be taught by CLT as it conflicts with teachers' dominant roles in the classroom in which they expect students to be docile and passive. In such a situation, they assume that the best teaching approach is the grammar-translation which is a teacher-centered approach. A further possible explanation of the unsuitability and the dispreference of CLT might be due to its burdensome responsibilities since teachers should organise and prepare extra authentic materials which can be sometimes quite challenging as teachers have non-teaching responsibilities. Moreover, CLT needs motivated students who communicate in their L2 all the class time not in their mother tongue. It also might be that teachers either do not know the benefits of using these approaches or they have not been trained in how to use them in the language classroom. An additional explanation is likely to be related to the fact that some teachers presume that knowledge is transferred not acquired. Thus, CLT cannot help any more as a teacher-centered approach can. Finally, they probably suppose that there may be no optimal pedagogical approaches across context and time. Consequently, language teachers should flexibly implement different approaches not only CLT. Such explanations may lead to assume that the tendency of unsuitability and dispreference of CLT is due to practical constraints which can be solved. Having such constraints put into consideration and determined the solutions, the implementation of CLT would be sometimes suitable and preferable.

With respect to the teachers' roles and needs in the implementation of CLT, significant agreements have been showed in a variety of statements such as teachers ought not to correct students' mistakes unless they breakdown the communication, teachers have to encourage their students to learn by themselves through struggling to communicate, teachers have non-teaching responsibilities which may lead to the improper preparation for the lessons and teachers should be trained to effectively implement the CLT. An inference may be drawn from these shown agreements is that these participants have a positive attitude towards the implementation of CLT.

As the provided responses on the adequacy of educational environment to implementing the CLT revealed, teachers have a positive attitude despite the challenges that might encounter them. The positive attitude can be inferred as the respondents showed agreements not only on the concentration of textbook on the language skills but also on the insufficiency of timetable and the impropriety of textbooks in exams preparation. Moreover, respondents revealed disagreements in the suitability of classrooms for CLT as well as the suitability of students' number in the classroom as they can be obstacle in the implementation of CLT.

\section{Conclusion}

In conclusion, CLT enjoyed its worldwide recognition as a new approach to language teaching instead of the traditional language teaching approaches. It relies on optimal materials, good teaching and the general and individual strategies carried out by language learners. Moreover, it highly encourages learners to employ their target language to undertake specific functional task through a variety of activities such as discussion of meaning, structure grammaticality and concentration on interaction which play a vital role in language development.

As reviewed, although certain disadvantages and criticisms have been made against CLT, there are numbers of advantages associated with it. One advantage is that it assists L2 learners to use all language skills in a real-life context which potentially enables L2 learners to improve their language skills to use them in a variety of contexts. It also facilitates L2 learners to gain independence which help them to use the language without assistance in real-life situations.

The current findings showed that although the respondents indicated that the CLT cannot be the best language teaching approach and it is not appropriate to be adopted, the positive attitude can be implied through the teachers' responses in several statements such as L2 teachers ought to concentrate on the fluency rather than the accuracy. Moreover, L2 learners should be the centre of knowledge transmission while their teachers should be facilitators. Also, teachers ought not to correct students' mistakes unless they breakdown the communication as well as they have to encourage their students to adopt self-study skills through struggling to communicate. Furthermore, respondents showed agreements in several challenges that may affect the implementation of CLT as non-teaching responsibilities, the unsuitability of textbooks and classrooms as well as the insufficiency of timetable. These challenges can be classified as educational environment restraints inside and outside the classroom.

As shown, a few challenges precluding the implementation of this approach at King Abdulaziz University have to be solved. These challenges were classified into two categorises: practical and educational environment. Having them overcome, CLT is possibly a suitable and preferable approach which is really helpful to improve L2 learners' language skills. 


\section{Acknowledgment}

I owe a great debt to my colleague Dr. Saeed Fehaid for his beneficial discussions and suggestions. My special regards and profound acknowledgments are due to the participants for their time and valuable participation.

\section{References}

Breen, M., \& Candline, C. N. (1980). The Essentials of a Communicative Curriculum in Language Teaching. Applied Linguistics, 1(2), 89-112. https://doi.org/10.1093/applin/1.2.89

Ellis. R. (1982). Informal and Formal Approaches to Communicative Language Teaching. ELT Journal, 63(2), 73-81. https://doi.org/10.1093/elt/36.2.73

HKCDC (Hong Kong Curriculum Development Committee) (1981) Syllabuses for Primary Schools, Hong Kong.

Jean. J. (2009). Key issues in applying the communicative approach in Korea: Follow up after 12 years of implementation. English Teaching, 46, 123-151. https://doi.org/10.15858/engtea.64.4.200912.123

Jin. Y. (2007). Adapting Communicative Language Teaching Approach to China's Context. English Teaching, 4(10), 29-33.

Lee, S. M. (2005). The Pros and Cons of Task-based Instruction in Elementary English Class. English Teaching, 60(2), 185-205.

Li, D. F. (1997). Absolutely Not the Same: The Potential and Problems of Communicative Language Teaching in China', unpublished doctoral dissertation, University of Alberta.

Littlewood, W. (1981). Communicative Language Teaching. Cambridge: Cambridge University Press.

Littlewood, W. (2004). The Task-based Approach: Some Questions and Suggestions. ELT Journal, 58(4), 319-326. https://doi.org/10.1093/elt/58.4.319

Nunan, D. (2004). Task-based Language Teaching. Cambridge: Cambridge University Press. https://doi.org/10.1017/CBO9780511667336

Penner, J. (1995). Change and Conflict: Introduction of the Communicative Approach in China. TESL Canada Journal, 12(2), 1-17. https://doi.org/10.18806/tesl.v12i2.649

Richards, J., \& Rodgers, T. (2001). Approaches and Methods in Language Teaching. Cambridge: Cambridge University Press. https://doi.org/10.1017/CBO9780511667305

Seedhouse. P. (1999). Task-based Interaction. ELT Journal, 53(3), 149-155. https://doi.org/10.1093/elt/53.3.149

Sun, G., \& Cheng, L. (2002). From Context to Curriculum: A Case Study of Communicative Language Teaching in China. TESL Canada journal/ revue TESL du Canada, 19(2), 67-86. https://doi.org/10.18806/tesl.v19i2.930

Swan, M. (1985). A Critical Look at the Communicative Approach (1). ELT Journal, 39(1), 2-12. https://doi.org/10.1093/elt/39.1.2

Widdowson, H. G. (1978). Teaching Language as Communication. Oxford: Oxford University Press.

Wilkins, D. A. (1972). The Linguistic and Situational Content of the Common Core in a Unit/credit System. MS. Strasbourg: Council Europe.

\section{Copyrights}

Copyright for this article is retained by the author(s), with first publication rights granted to the journal.

This is an open-access article distributed under the terms and conditions of the Creative Commons Attribution license which permits unrestricted use, distribution, and reproduction in any medium, provided the original work is properly cited. 